\title{
LEPTIN AND GHRELIN - THE NEW OLD PLAYERS IN OBESITY AND DEPRESSION
}

\author{
Rositsa V. Sandeva, \\ Stanislava M. Mihaylova, \\ Gergana N. Sandeva ${ }^{1}$
}

Department of Physiology, Pathophysiology and Pharmacology, Medical Faculty, Trakia University, Stara Zagora

${ }^{1}$ Department of Hygiene, Infectious

Diseases, and Epidemiology, Medical Faculty, Trakia University, Stara Zagora
Corresponding Author:

Rositsa V. Sandeva

Department of Physiology,

Pathophysiology and Pharmacology

Medical Faculty, Trakia University,

11 Armeiska str.

Stara Zagora, 6000

Bulgaria

e-mail: rossisandeva@yahoo.com

Received: November 10, 2014

Revision received: December 15, 2014

Accepted: December 19, 2014

\begin{abstract}
Summary
The participation of the anorexigenic peptide leptin and the orexigenic peptide ghrelin in the pathogenesis of metabolic syndrome and obesity is well studied. In this review, we are taking a look at the structure, anatomical expression, regulation, receptors and physiological functions of these two neuropeptides. Leptin is produced almost exclusively in adipose tissue. It acts on the brain and is a key element in long-term regulation of energy balance. Leptin suppresses appetite and reduces body weight. Besides its central effects, important aspects of its action on peripheral tissues have been discovered recently: direct regulation of immune cells, pancreatic beta cells, adipocytes and muscle cells. Ghrelin is an endogenous ligand for the active form of the growth hormone receptor (GHS-R1a) and stimulates food intake and growth hormone secretion. We focus on the role of leptin and ghrelin in central nervous system neural mechanisms that are associated with depression. Studying new aspects of these two neuropeptides aims to expand our knowledge of the pathogenesis and therapeutic approaches to diseases with which they are associated: obesity, depression, type 2 diabetes, essential hypertension, and more.

Keywords: leptin, ghrelin, obesity, depression.
\end{abstract}

\section{Introduction}

The participation of the anorexigenic peptide leptin and the orexigenic peptide ghrelin in the regulation of energy homeostasis and the pathogenesis of metabolic syndrome and obesity is well studied. Recent studies have linked these neuropeptides to the regulation of mood and emotion. Therefore, we focused on the leptin and ghrelin hypothesis of depression, examining the potential link between mood disorders and obesity.

We concentrated on the structure, anatomical expression, regulation, receptors and physiological functions of leptin and ghrelin. We also investigated their involvement in the control of important functions such as immunity, reproduction, hematopoiesis and angiogenesis, bone growth, in the pathogenesis of the obstructive sleep apnoea syndrome (OSAS), polycystic ovary syndrome, and more. 


\section{Structure}

Leptin is a peptide hormone discovered in 1994 and encoded by the obesity gene (ob-gene) as a protein consisting of 167 amino acids. Secreted by adipocytes, leptin circulates in blood as a protein composed of 146 amino acids with a weight of 16 kilodaltons. Its $\mathrm{N}$-terminal region is the most important for receptor binding and biological functions.

Ghrelin is a 28 -amino acid neuropeptide, originally isolated from porcine stomach extracts by Kojima et al. in 1999 [1]. It is an endogenous ligand for the active form of the growth hormone receptor GHS-R1a and stimulates the hormone's secretion, as well as food intake [2].

\section{Anatomical Expression}

Leptin synthesis occurs primarily in white adipose tissue, although recent studies have shown that it is also produced in brown adipose tissue (its role there is still unclear). There are gender differences in plasma levels of leptin, possibly caused by the higher concentration of estrogen in women. Immunohistochemistry methods have established that leptin in the stomach is secreted by two cell populations gastric chief cells and enteroendocrine cells. It is also produced by mammary epithelial cells, the ovaries, placenta and some fetal tissues [3].

Ghrelin occurs in two forms in tissues and plasma - acyl-modified and des-acyl ghrelin. In the mucosal layer of the stomach (primarily the fundus) there are X/A-like cells, whose granules contain ghrelin [4]. Small amounts of such cells that increase after births have also been found in fetal stomach. Ghrelin-immunoreactive cells have also been found in the intestines, where ghrelin concentration decreases from the duodenum to the colon.

Cells synthesizing this peptide in the pancreas (alpha, beta or newly discovered epsilon cells) remain a topic of debate. Unlike gastric ghrelin, pancreatic ghrelin is high in the prenatal period and decreases after birth. In addition, its levels are not affected by fasting. Ghrelin concentration in the brain is very low, found mainly in the hypothalamic nucleus arcuatus associated with appetite control. Ghrelin has also been detected in the pituitary gland, where it affects the secretion of growth hormone via auto- and paracrine signaling. Ghrelin peptides have also been identified in pituitary tumors.
Clearance and degradation of ghrelin occurs in the kidney. In patients with end-stage renal failure, plasma ghrelin concentration correlates with that of serum creatinine and is three times higher than that in patients with normal renal function.

\section{Regulation}

Leptin in the serum is positively correlated to BMI [5] and body fat [6], such that in obese individuals its levels are higher in females. Lee et al. have established that another important factor is the size of adipocytes, which also exhibits a positive correlation to leptin levels [7]. The sympathetic nerves inhibit leptin biosynthesis via $\beta 1$ - and $\beta 2$-adrenergic receptors [8], while insulin, prolactin and thyroid stimulating hormone stimulate it $[9,10]$. Short-chain fatty acids enhance leptin secretion through G-protein coupled receptors [11].

Physical exercise has a varied effect on leptin levels depending on the intensity and type of exercise, the duration of training, and other factors [12].

Leptin acts at the level of the hypothalamic nucleus arcuatus by interfering with the activity of two groups of neurons: anorexigenic POMC (pro-opiomelanocortin) - neurons that coexpress CART (cocaine-amphetamine-regulated transcript) and orexigenic AgRP (agouti-related peptide) - neurons that co-express neuropeptide Y. Leptin suppresses appetite by stimulating POMC neurons (it increases energy consumption and the release of alpha-melanocyte stimulating hormone), and inhibiting neuropeptide $\mathrm{Y}$ gene expression.

Ghrelin is the strongest orexigenic peptide [4]. While most orexigenic peptides originate from the brain and are only active when injected into the brain, ghrelin is active even by peripheral administration leading to an increase in appetite in rodents and humans [2]. At the level of nucleus arcuatus, presynaptic ghrelin-producing neurons stimulate the secretion of neuropeptide $Y$ and agouti-related peptide, thus increasing appetite $[13,14]$. In the paraventricular nucleus, ghrelin also stimulates the release of neuropeptide Y, which inhibits the secretion of the neurotransmitter GABA, resulting in increased corticotropin releasing hormone, and subsequently increased adrenocorticotropic hormone and cortisol. Ghrelin acts through the vagal autonomic nervous system. Vagotomy 
eliminates its orexigenic effect.

\section{Receptors}

The leptin receptor is a single membrane-bound protein, which belongs to type I cytokine receptors [15]. It functions by means of Janus kinases and STATs (signal transducers and activators of transcription). There are 6 known isoforms of ob-R receptors, grouped into three classes - long (OB-Rb), short (OB-Ra, c, d, f) and soluble - OB-Re. The long isoforms regulate STAT-5 and ribosomal protein S-6, and the role of the short isoforms remains unclear [16]. Mice and humans that are genetically null for leptin synthesis (ob/ob mice) or leptin receptor $\mathrm{b}(\mathrm{db} / \mathrm{db}$ mice) develop secondary obesity due to an increased appetite and decreased energy utilization.

The long leptin receptor $\mathrm{LRb}$ is found in large numbers in the arcuate, dorsomedial, ventromedial, and ventral premamillary hypothalamic nuclei. The chemical or physical ablation of these nuclei leads to an increased appetite and neuroendocrine disorders similar to those in ob/ob and $\mathrm{db} / \mathrm{db}$ mice. This indicates that the aforementioned nuclei, or the so-called "satiety center", are a critical location for leptin function [17].

The ghrelin receptor GHS-R is a typical Gprotein coupled receptor with 7 transmembrane domains. The mRNA of the ghrelin receptor is expressed mainly in the nucleus arcuatus, the ventromedial nucleus and in the hippocampus (an area associated with learning and memory). The ghrelin receptor is highly sensitive to growth hormone and its expression is increased in GHdeficient rats ( $\mathrm{dw} / \mathrm{dw}$ rats). Treatment of these rats with $\mathrm{GH}$ reduces the expression of the receptor. The mRNA of ghrelin receptors is also expressed in some peripheral organs such as the heart, lungs and liver, kidney, pancreas, stomach, intestine, adipose tissue, and immune cells. This indicates that ghrelin has diverse functions in these organs. Ghrelin plasma levels increase 20$30 \mathrm{~min}$ before meals. Thus, in obesity ghrelin receptor antagonists could be used to block this ghrelin stimulus and thereby reduce meal size [18].

\section{Physiological functions}

Leptin is a key component in the regulation of appetite and energy homeostasis [19]. The fact that depressive disorders manifest themselves with a change in appetite and food intake, has drawn the attention of scientists to the participation of leptin in these disorders [20]. Mice and rats exposed to chronic stress develop behavioral and endocrine changes similar to those seen in human depression. Their plasma leptin levels are reduced. One model of depressive behavior in chronically stressed animals displays a reduced preference for sucrose, which is considered to be an analogue of anhedonia (lack of pleasure), a key symptom of depression. Systemic application of leptin cures this disorder.

Leptin in depressed patients occurs at various levels [21]. Deuschle et al. have found that plasma leptin concentrations do not differ between patients with depression and healthy controls [22]. Other authors have reported a decrease of leptin in these patients. Milaneschi et al. have established a connection between the high levels of leptin, abdominal obesity and the increased incidence of depression, which is associated with leptin resistance [23]. In the modern world, it has been found that obesity increases depression in humans by $20 \%$, whereby the high levels of leptin indicate leptin resistance.

One of the possible mechanisms for the antidepressant effect of leptin is its effect on the hypothalamic-pituitary-adrenal axis. The recently established neurotrophic function of leptin may play a role in improving depressive symptoms. Patients with depression revealed atrophy of certain limbic structures, including the hippocampus and the prefrontal cortex. New research will clarify the possible use of leptin as an antidepressant agent.

The following systemic effects of leptin have also been identified:

- It stimulates angiogenesis (via fibroblast and vascular endothelial growth factor) and vascular permeability.

- It has an effect on the immune system by directly affecting $\mathrm{T}$-cells containing Lrb.

- It regulates the proinflammatory immune response (stimulating the secretion of cytokines IL-6, IL-10 and TNF- $\alpha$ ) and apoptosis.

- It participates in the regulation of hematopoiesis and bone growth (an antiosteogenic effect via the sympathetic nervous system).

- It plays a key role in reproduction - the beginning of puberty, fertility, pregnancy. 
$\mathrm{Ob} / \mathrm{ob}$ and $\mathrm{db} / \mathrm{db}$ mice with obesity and infertility improve after treatment with leptin. The effect is related to its influence on the hypothalamic-pituitary axis and the direct stimulation of the secretion of luteinizing and follicle-stimulating hormone.

- Leptin resistance is associated with obstructive sleep apnoea syndrome [24, 25] and polycystic ovary syndrome [26, 27].

Ghrelin has other interesting features alongside its orexigenic properties [28]. In 2008, Lutter et al. found that chronic stress in mice leads to an increase in ghrelin, which reduces the signs of depression and anxiety disorder [29]. Later his team demonstrated that in humans, a high level of ghrelin results in the formation of new neurons in the hippocampus (the center related to mood, memory, and eating behavior). Increasing the effect of ghrelin on the hippocampus by using a product directly stimulating the production of new neurons in this area (chemical codename P7C3 2010) has shown promising results in the treatment of Parkinson's disease, Alzheimer's disease, brain injury, amyotrophic lateral sclerosis and others [30].

In their experiments Chuang et al. injected ghrelin into overfed fed mice and found that the mice exhibited a strong preference to an empty room where they previously found high-fat meals [31]. The mice fled a room in which they received standard low-calorie portions. Their behavior was similar to the wish to obtain pleasure or reward in other animal experiments, which have been used to study alcohol or cocaine addiction. Modern stressed life in humans leads to increased ghrelin and eating for comfort, manifested in an increased desire for greasy and sweet food. Ghrelin has an antidepressant effect, but it causes people to overeat even when they are full. Blocking its synthesis might lead to weight loss, but it will have an adverse effect on mood.

Other effects of ghrelin are also of interest:

- It blocks interleukin-1 beta-induced anorexia, suggesting a clinical application in medical and postoperative induced anorexia, such as the one occurring in cancer patients.

- In patients who have undergone gastric bypass surgery, ghrelin concentration in plasma decreases by $70 \%$, resulting in a lack of hyperphagia and decreased body weight [32]. One hypothesis states that direct contact between the gastric mucosa and food is a leading factor in the secretion of ghrelin [33].

- By stimulating the vagal nerve, ghrelin increases the secretion of hydrochloric acid and the motility of the stomach.

- The cardiovascular functions of this neuropeptide are associated with lower blood pressure, left ventricular remodeling, and improvement in the left ventricular function.

- Total gastrectomy leads to a 70\% reduction in pre-operations levels of ghrelin because of compensatory output from the intestines and the pancreas. Post-operation osteopenia indicates that ghrelin may also be involved in the control of bone growth.

- Plasma levels of ghrelin are low in patients with obesity and irritable bowel syndrome, and high in thin people, patients with bulimia and anorexia nervosa. In the latter, high ghrelin increases ACTH, prolactin and cortisol, which explains the amenorrhea and behavioral changes in these patients.

- High levels of ghrelin also appear in PraderWilli syndrome, a genetic disease associated with dysfunction of some hypothalamic areas (including the center of appetite), which explains the resulting hyperphagia [34, 35].

- Ghrelin levels increase after showing pictures of food to volunteers [36]. These findings support the hypothesis that environmental factors contribute to eating behavior in modern society, where visual presentation of food products is common.

\section{Conclusions}

The clinical applications of the neuropeptides leptin and ghrelin are diverse: from eating disorders, gastrointestinal and cardiovascular diseases to catabolic conditions, depression, anxiety and diseases associated with aging. Future studies of these neuropeptides will help

\section{References}

1. Kojima M, Hosoda H, Date Y. Ghrelin is a growthhormonereleasing acylated peptide from stomach. Nature.1999;402:656-60.

2. Wren AM, Small CJ, Abbott CR, Dhillo WS, Seal LJ, Cohen MA et al. Ghrelin causes hyperphagia and obesity in rats. Diabetes. 2001;50:2540-7.

3. Smith-Kirwin SM, O'Connor DM, De Johnston J, Lancey ED, Hassink SG, Funanage VL. Leptin expression in human mammary epithelial cells and breast milk. J Clin Endocrinol Metab. 
1998;83(5):1810-3.

4. Kojima M, Kangawa K. Ghrelin: structure and function. Physiol Rev. 2005;85(2):495-522.

5. Paul RF, Hassan M, Nazar HS, Gillani S, Afzal N, Qayyum I. Effect of body mass index on serum leptin levels. J Ayub Med Coll Abbottabad. 2011;23(3):40-43.

6. Hellström L, Wahrenberg H, Hruska K, Reynisdottir S, Arner P. Mechanisms behind gender differences in circulating leptin levels. J Intern Med. 2000;247(4):457-62.

7. Lee MJ, Wang Y, Ricci MR, Sullivan S, Russell $\mathrm{CD}$, Fried SK. Acute and chronic regulation of leptin synthesis, storage, and secretion by insulin and dexamethasone in human adipose tissue. Am J Physiol Endocrinol Metab. 2007;292(3):858-64.

8. Scriba D, Aprath-Husmann I, Blum WF, Hauner $\mathrm{H}$. Catecholamines suppress leptin release from in vitro differentiated subcutaneous human adipocytes in primary culture via beta 1 - and beta2adrenergic receptors. Eur J Endocrinol. 2000;143(3):439-45.

9. Menendez C, Baldelli R, Camiña JP, Escudero B, Peino R, Dieguez C, et al. TSH stimulates leptin secretion by a direct effect on adipocytes. J Endocrinol. 2003;176(1):7-12.

10. Gualillo O, Lago F, Garcia M, Menendez C, Senaris R, Casanueva F et al. Prolactin stimulates leptin secretion by rat white adipose tissue. Endocrinology. 1999; 140(11):5149-53.

11. Xiong Y, Miyamoto N, Shibata K, Valasek MA, Motoike T, Kedzierski RM, et al. Short-chain fatty acids stimulate leptin production in adipocytes through the G protein-coupled receptor GPR41. PNAS. 2004;101(4):1045-50.

12. Vatansever-Ozen S, Tiryaki-Sonmez G, Bugdayci G, Ozen G. The effects of exercise on food intake and hunger: relationship with acylated ghrelin and leptin. Journal of Sports Science and Medicine. 201;10:283-91.

13. Kageyama H, Takenoya F, Shiba K, Shioda S. Neuronal circuits involving ghrelin in the hypothalamus-mediated regulation of feeding. Neuropeptides. 2010;44(2):133-8.

14. Kamegai J, Tamura H, Shimizu T, Ishii S, Sugihara $\mathrm{H}$, Wakabayashi I. Chronic central infusion of ghrelin increases hypothalamic neuropeptide $\mathrm{Y}$ and Agouti-related protein mRNA levels and body weight in rats. Diabetes. 2001;50(11):2438-43.

15. Tartaglia LA, Dembski M, Weng X, Deng N, Culpepper J, Devos $\mathrm{R}$ et al. Identification and expression cloning of a leptin receptor, OB-R. Cell. 1995;83(7):1263-71.

16. Münzberg H, Björnholm M, Bates SH, Myers MG. Leptin receptor action and mechanisms of leptin resistance. CMLS Cellular and Molecular Life Sciences. 2005;62(6):642-652.

17. Holst B, Schwartz T. Constitutive ghrelin receptor activity as a signaling set-point in appetite regulation. Trends in Pharmacological Sciences.
2004;25(3):113-7.

18. Holst B, Cygankiewicz A, Jensen TH, Ankersen M, Schwartz TW. High constitutive signaling of the ghrelin receptor-identification of a potent inverse agonist. Mol Endocrinol. 2003; 17(11):2201-10

19. Attele AS, Shi ZQ, Yuan CS. Leptin, gut and food intake. Biochem Pharmacol. 2002;63(9):1579-83.

20. Lu XY. The leptin hypothesis of depression: a potential link between mood disorders and obesity? Curr Opin Pharmacol. 2007;7(6):648-52.

21.Lawson EA, Miller KK, Blum JI, Meenaghan E, Misra M, Eddy KT, et al. Leptin levels are associated with decreased depressive symptoms in women across the weight spectrum, independent of body fat. Clin Endocrinol (Oxf). 2012;76(4):520-5.

22. Deuschle M, Blum WF, Englaro P, Schweiger U, Weber B, Pflaum CD, et al. Plasma leptin in depressed patients and healthy controls. Hormone and Metabolic Research. 1996;28:714-7.

23. Milaneschi Y, Simonsick FM, Penniux BW. Leptin, abdominal obesity and onset of depression in older men and women. J Clin Psychiatry. 2012;73(9):1205-11.

24. Phillips BG, Kato M, Narkiewicz K, Choe I, Somers VK. Increases in leptin levels, sympathetic drive, and weight gain in obstructive sleep apnea. Am J Physiol Heart Circ Physiol. 2000; 279(1):234-7.

25.Sanner BM, Kollhosser P, Buechner N, Zidek W, Tepel M. Influence of treatment on leptin levels in patients with obstructive sleep apnoea. Eur Respir J. 2004;23(4):601-4.

26. Brzechffa PR, Jakimiuk AJ, Agarwal SK, Weitsman SR, Buyalos RP, Magoffin DA. Serum immunoreactive leptin concentrations in women with polycystic ovary syndrome. JCEM. 1996;81(11):4166-9.

27. Lecke SB, Mattei F, Morsch DM, Spritzer PM. Abdominal subcutaneous fat gene expression and circulating levels of leptin and adiponectin in polycystic ovary syndrome. Fertil Steril. 2011;95(6):2044-9.

28. Rindi G, Torsello A, Locatelli V, Solcia E. Ghrelin expression and actions: a novel peptide for an old cell type of the diffuse endocrine system. Exp Biol Med (Maywood). 2004;229(10):1007-16.

29. Lutter M, Sakata I, Osborne-Lawrence S, Rovinsky SA, Anderson JG, Jung S et al. The orexigenic hormone ghrelin defends against depressive symptoms of chronic stress. Nat Neurosci. 2008;11(7):752-3.

30. Walker AK, Rivera PD, Wang Q, Chuang JC, Tran $\mathrm{S}$, Osborne-Lawrence S et al. The P7C 3 class of neuroprotective compounds exerts antidepressant efficacy in mice by increasing hippocampal neurogenesis. Mol Psychiatry. 2014. doi: 10.1038/mp.2014.34. 
31. Chuang JC, Perello M, Sakata I, OsborneLawrence S, Savitt JM, Lutter M, et al. Ghrelin mediates stress-induced food-reward behavior in mice. J Clin Invest. 2011;121(7): 2684-92.

32. Cummings DE, Weigle DS, Frayo RS, Breen PA, Ma MK, Dellinger EP et al. Plasma ghrelin levels after diet-induced weight loss or gastric bypass surgery. N Engl J Med. 2002;346:1623-30.

33. Buchwald $H$, Williams SE. Bariatric surgery worldwide 2003. Obes Surg. 2004; 14:1157-64.

34. Bizzarri C, Rigamonti AE, Luce A, Cappa M, Cella
SG, Berini J et al. Children with Prader-Willi syndrome exhibit more evident meal-induced responses in plasma ghrelin and peptide YY levels than obese and lean children. Eur J Endocrinol. 2010;162:499-505.

35. Goldstone AP. Prader-Willi syndrome: advances in genetics, pathophysiology and treatment. Trends Endocrinol Metab. 2004;15:12-20.

36. Schüssler P, Kluge M, Yassouridis A, Dresler M, Uhr M, Steiger A. Ghrelin Levels Increase After Pictures Showing Food. Obesity. 2012; 20(6):1212-7. 